\title{
Blackstart of Power Grids with Inverter-Based Resources
}

Himanshu Jain, Gab-Su Seo, Eric Lockhart, Vahan Gevorgian, and Benjamin Kroposki

Himanshu.Jain@nrel.gov

3-6 August 2020 


\section{Background}

- What did we do in this paper?

- Performed simulations to evaluate the technical feasibility of inverter-based resource-(IBR-) driven blackstart

- Developed a model of current-limited grid-forming inverters to simulate IBRdriven blackstart of a motor.

- Motivation

- Interest in industry to understand the technical potential and associated costs of using IBRs for blackstart

- Limited existing research on modeling/simulation to understand the performance of IBRs for blackstart. 


\section{Approach}
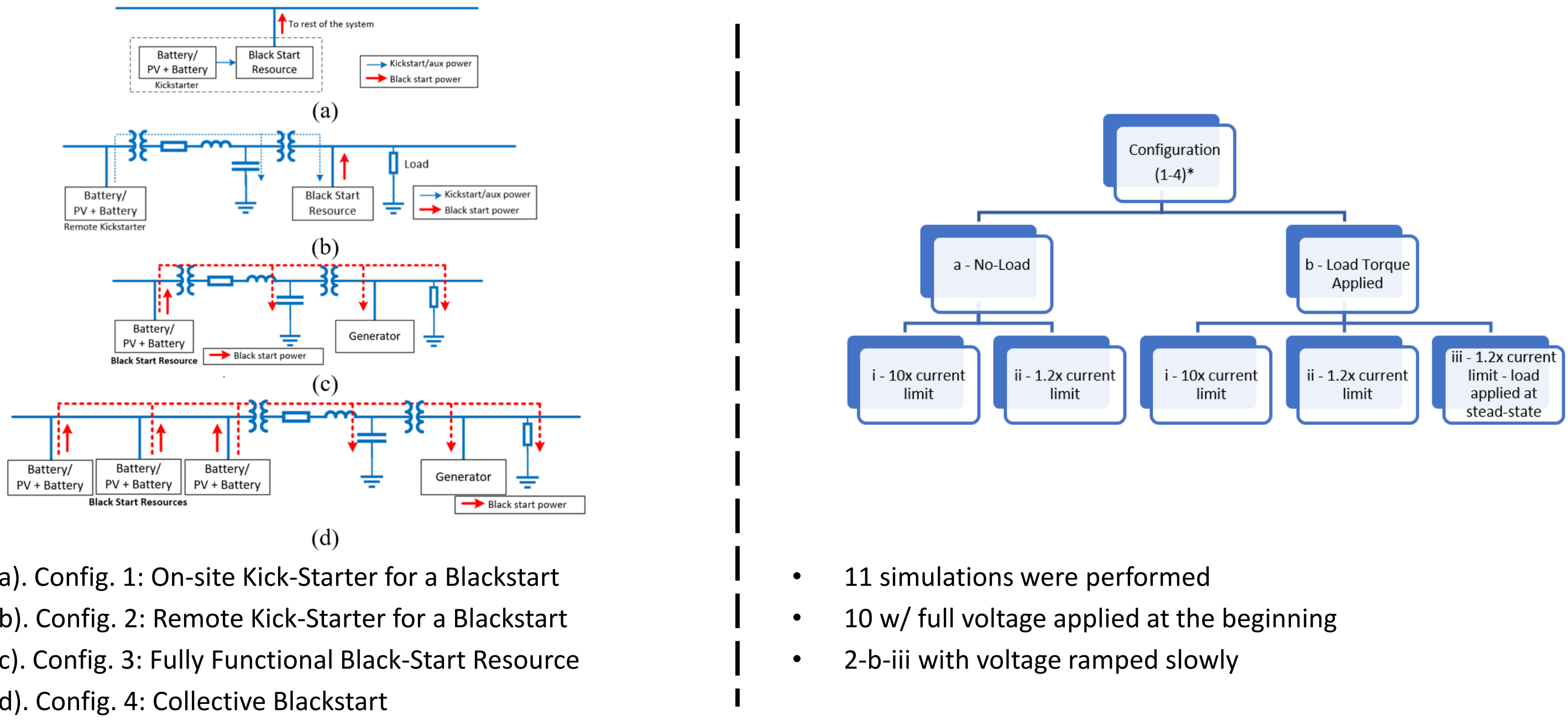

- 11 simulations were performed

- $10 \mathrm{w} /$ full voltage applied at the beginning

- 2-b-iii with voltage ramped slowly 


\section{Results}

Full Voltage Applied at $\mathrm{t}=0$ Seconds

\begin{tabular}{|c|c|c|c|}
\hline $\begin{array}{c}\text { Simulation label } \\
\text { from Fig. 5 }\end{array}$ & $\begin{array}{c}\text { Voltage (Mean } \\
\text { 3-phase, voltage } \\
\text { in p.u.) }\end{array}$ & $\begin{array}{c}\text { Current (Mean } \\
\text { 3-phase, current } \\
\text { in p.u. })\end{array}$ & $\begin{array}{c}\text { Start Time } \\
\text { (s) }\end{array}$ \\
\hline 1/a/i & 0.98 & 4.00 & 1.86 \\
\hline $1 / \mathrm{b} / \mathrm{i}$ & 0.97 & 4.03 & 4.50 \\
\hline $1 / \mathrm{b} / \mathrm{ii}$ & 0.29 & 1.21 & No start \\
\hline $1 / \mathrm{b} /$ iii & 0.29 & 1.18 & 20.67 \\
\hline $2-3 / \mathrm{a} / \mathrm{i}$ & 0.95 & 4.13 & 1.89 \\
\hline $2-3 / \mathrm{b} / \mathrm{i}$ & 0.96 & 4.17 & 4.75 \\
\hline $2-3 / \mathrm{b} /$ ii & 0.28 & 1.21 & No start \\
\hline $2-3 / \mathrm{b} /$ iii & 0.27 & 1.19 & 22.43 \\
\hline $4 / \mathrm{b} / \mathrm{ii}$ & 0.72 & 1.05 per IBR & Unstable \\
\hline $4 / \mathrm{b} / \mathrm{iii}$ & 0.71 & 1.03 per IBR & 3.40 \\
\hline
\end{tabular}

\section{Ramped Voltage Applied}

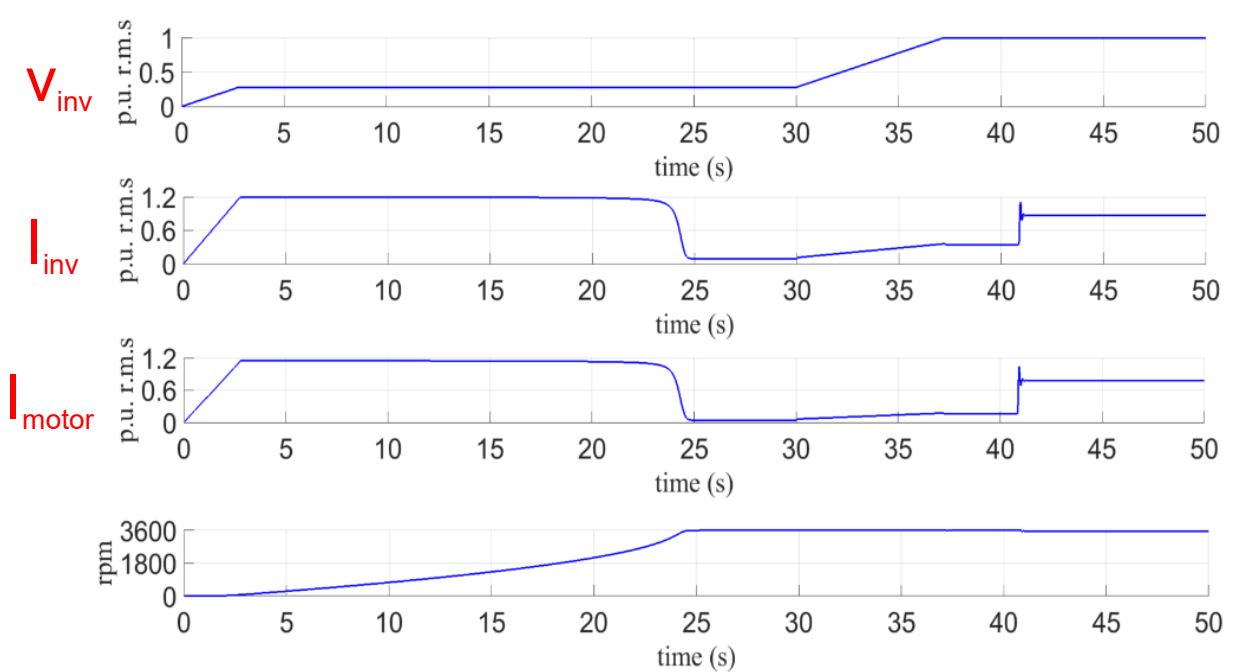

- No load, $1.2 X$ current limit, motor starts (green shaded rows)

- Load applied after steady state, $1.2 X$ current limit, motor stalls in 1/2-3-a/b-iii configuration but picks up load at 1.5X (see Fig. 7 in the paper); also picks up in Configuration 4 with three IBRs (green shaded rows)

- Load applied from the beginning, 1.2X current limit, motor stalls or reaches an unstable equilibrium point (red shaded rows)

- Ramped voltage, $1.2 X$ current limit, load pickup fails if applied from the beginning. Load is picked up if applied after steady state is reached. 


\section{Conclusions/Future Work}

- Under the ideal conditions simulated, IBRs with modest overcurrent limits (1.2-1.5 times rated current) can blackstart motors if unloaded or loaded after steady state is reached.

- IBRs might be able to start soft-starter equipped motors with significantly lower overcurrent limits.

- Future research should focus on high-fidelity modeling of IBR's inverters, loads to be blackstarted, and protective relays.

This work was authored by the National Renewable Energy Laboratory, operated by Alliance for Sustainable Energy, LLC, for the U.S. Department of Energy (DOE) under Contract No. DE-AC36-08GO28308. Funding provided by U.S. Department of Energy Office of Energy Efficiency and Renewable Energy Solar Energy Technologies Office. The views expressed in the article do not 